\title{
Biosimilars: Are They Ready for Primetime in the United States?
}

\author{
Bradford R. Hirsch, MD, and Gary H. Lyman, MD, MPH, Durham, North Carolina
}

\author{
Key Words \\ Biosimilars, follow-on biologics, subsequent-entry biologics, \\ generics, myeloid growth factors, health policy
}

\begin{abstract}
The introduction of alternative versions of biologic products, also known as biosimilars, into the United States market has been gaining increasing visibility as patents for many agents are nearing expiration. Unlike generics, which are regulated under the Hatch-Waxman legislation passed in 1984, the approval process for biosimilars in the United States has not been defined. In 2004, the European Union established a regulatory pathway for these agents, and the FDA is now following suit. The economic implications are large, with $\$ 66.9$ billion spent on the top 20 biologics in 2009. Of the top 10 biologics, 6 are routinely used in oncology. As the regulatory requirements are debated, several critical issues must be resolved. The most obvious is that the agents must be shown to be comparable to the original biologic they intend to replace. Knowledge of pharmacokinetic parameters alone will not be adequate, but the amount of clinical data required by the FDA remains unclear. The regulations will define the ease with which a biosimilar can be brought to market, and the associated costs of trials will influence the ultimate price of the medications. Balancing the needs of the relevant stakeholders is critical to ensure
\end{abstract}

From the Department of Medicine, Duke University and the Duke Cancer Institute, Durham, North Carolina.

Submitted March 2, 2011; accepted for publication May 4, 2011.

Dr. Hirsch has disclosed that he has no financial interests, arrangements, or affiliations with the manufacturers of any products discussed in this article or their competitors. Dr. Lyman has disclosed that he is the principal investigator on a research grant for Duke University from Amgen, Inc. He has no other financial interests, arrangements, or affiliations with manufacturers of any products discussed in this article or their competitors.

Correspondence: Gary H. Lyman, MD, MPH, Duke University and the Duke Cancer Institute, 2424 Erwin Road, Suite 205, Durham, NC 27705.

E-mail: gary.lyman@duke.edu

\section{EDITOR}

Kerrin M. Green, MA, Assistant Managing Editor, Journal of the National Comprehensive Cancer Network

Disclosure: Kerrin M. Green, MA, has disclosed no relevant financial relationships. patient safety while controlling costs, improving access, and encouraging innovation. This is not an easy balance to strike. (JNCCN 2011;9:934-943)

\section{Medscape: Continuing Medical Education Online}

\section{Accreditation Statement}

This activity has been planned and implemented in accordance with the Essential Areas and policies of the Accreditation Council for Continuing Medical Education through the joint sponsorship of Medscape, LLC and JNCCN - The Journal of the National Comprehensive Cancer Network. Medscape, LLC is accredited by the ACCME to provide continuing medical education for physicians.

\begin{abstract}
Medscape
Medscape, LLC designates this Journal-based CME activity for a maximum of 1.0 AMA PRA Category 1 Credit(s) ${ }^{\mathrm{TM}}$. Physicians should claim only the credit commensurate with the extent of their participation in the activity. All other clinicians completing this activity will be issued a certificate of participation. To participate in this journal CME activity: (1) review the learning objectives and author disclosures; (2) study the education content; (3) take the post-test with a $70 \%$ minimum passing score and complete the evaluation at www.medscape. org/journal/jnccn; (4) view/print certificate.
\end{abstract}

Release date: August 4, 2011; Expiration date: August 4, 2012.

\section{AUTHORS AND CREDENTIALS}

Bradford R. Hirsch, MD, Department of Medicine, Duke University; Duke Cancer Institute, Durham, North Carolina

Disclosure: Bradford R. Hirsch, MD, has disclosed no relevant financial relationships.

Gary H. Lyman, MD, MPH, Department of Medicine, Duke University; Duke Cancer Institute, Durham, North Carolina

Disclosure: Gary H. Lyman, MD, MPH, has disclosed the following relevant financial relationships: Receives research support from Amgen.

\section{CME AUTHOR}

Charles P. Vega, MD, Associate Professor; Residency Director, Department of Family Medicine, University of California, Irvine

Disclosure: Charles P. Vega, MD, has disclosed no relevant financial relationships. 


\section{Learning Objectives}

Upon completion of this activity, participants will be able to:

- Describe current regulation of biologic agents

- Analyze the system for the approval of biosimilars in Europe

- Evaluate the potential economic impact of biosimilars

- Distinguish the most promising system for monitoring the quality of biosimilars

\section{Background on Biosimilars}

As the name implies, biologics encompass a range of medicinal products that are manufactured via biologic pathways instead of chemical synthesis. They often rely on recombinant DNA techniques and are more intricate and complex than chemical drugs. The initial biologics included erythropoietin, insulin, and growth hormones, yet the diversity of agents and their associated revenues have grown significantly since their introduction. Between 1995 and 2007, 136 biopharmaceuticals were approved in the United States and 105 in the European Union (EU). ${ }^{1}$ Unlike small molecules, which are chemically synthesized and can be reliably replicated, biologics are produced using living cell cultures in which even small variations can change the efficacy, immunogenicity, and toxicity of the final product..$^{2-4}$

Cancer treatment is the leading indication for biologics, with monoclonal antibodies alone accounting for $\$ 18.2$ billion in sales in 2009.5 When agents used in supportive care are included, 6 of the top 10 biologics according to revenue are used in oncology (Table 1). ${ }^{5}$ Traditionally, biologics have been approved under the Public Health Service Act (PHSA), whereas generics were approved under the Federal Food, Drug, and Cosmetic Act (FDCA). Under the PHSA, biologic license applications require significant preclinical and clinical data to prove safety, quality, and efficacy. Unlike the FDCA, the PHSA does not have an abbreviated process for approving follow-on agents. However, as patents on biologics expire, competing companies are planning to introduce new formulations of these previously introduced therapeutic proteins. These agents, referred to by several names, including biosimilars, biogenerics, follow-on biologics, and subsequent-entry biologics, will enter the United States market with patent expirations over the next few years, as they did in Europe in 2007.

Biosimilars will need more extensive clinical testing than generics to ensure comparability because of the intricacy and variability inherent in their production. The Patient Protection and Affordable Care Act, which passed in March of 2010, began the process of defining the evidentiary requirements for approval of these agents, amending the PHSA to allow for an abbreviated process. It authorized the FDA to define the approval procedure; however, the specifics are not yet finalized. The legislation states that no clinically meaningful differences can exist between a biosimilar and its predecessor, but whether they are required to show comparability or true interchangeability remains to be seen. Although comparability could be proven by showing that the innovator and follow-on have no clinically significant differences, interchangeability was defined stringently under the Hatch-Waxman legislation as requiring that the new agent provide the same clinical result in any given patient. Clearly this is a high bar. After significant discussion, the innovator biologics were granted 12 years of data exclusivity before a biosimilar could be introduced to the market, which is meant to ensure appropriate economic incentives for continued research and development by industry.

In finalizing the FDA pathway, patient safety must take priority. The EU, Canada, and Japan have all implemented biosimilar legislation, which can be used as a blueprint. ${ }^{6,7}$ The production process of each

\begin{tabular}{|llll|}
\hline $\begin{array}{l}\text { Table } 1 \\
\text { in Oncology }\end{array}$ & $\begin{array}{l}\text { Six of the Top-10 } \\
\text { Biologics Used }\end{array}$ \\
\hline $\begin{array}{l}\text { Agent } \\
\text { (Trade Name) }\end{array}$ & Mechanism & $\begin{array}{l}\text { Sales } \\
\text { Rank }\end{array}$ & $\begin{array}{l}\text { 2009 Sales } \\
\text { (Billion) }\end{array}$ \\
\hline $\begin{array}{l}\text { Bevacizumab } \\
\text { (Avastin) }\end{array}$ & VEGF & 3 & US $\$ 5.8$ \\
$\begin{array}{l}\text { Rituximab } \\
\text { (Rituxan) }\end{array}$ & CD20 & 4 & US $\$ 5.7$ \\
$\begin{array}{l}\text { Epoetin alfa } \\
\text { (multiple) }\end{array}$ & EPO-R & 6 & US $\$ 5.0$ \\
$\begin{array}{l}\text { Trastuzumab } \\
\text { (Herceptin) }\end{array}$ & HER2/neu & 7 & US $\$ 4.9$ \\
$\begin{array}{l}\text { Pegfilgrastim } \\
\text { (Neulasta) }\end{array}$ & G-CSF & 9 & US $\$ 3.4$ \\
$\begin{array}{l}\text { Darbepoetin } \\
\text { alfa (Aranesp) }\end{array}$ & EPO-R & 10 & US $\$ 2.9$ \\
\hline
\end{tabular}

Abbreviations: EPO-R, erythropoietin receptor; G-CSF, granulocyte colony-stimulating factor; HER2/neu, human epidermal growth factor receptor 2; VEGF, vascular endothelial growth factor.

Data from Ledford H. 'Biosimilar' drugs poised to penetrate market. Nature 2010;468:18-19. 
Hirsch and Lyman

biologic is proprietary, and therefore cannot be perfectly replicated; even if the process was duplicated, it would be unlikely to result in an identical product because of variations in areas such as vectors, cell line development, and bioreactor conditions. ${ }^{2,4,8}$ Robust evidence generation is critical to ensure safety and efficacy, but cannot be too burdensome to dissuade market entry. Methods beyond traditional clinical trials are also likely to play a role, such as pharmacovigilance, which allows surveillance once an agent is on the market to monitor for safety signals.

The ideal pathway would allow a host of new entrants to enter the market with adequate demonstration of safety, efficacy, and competitive pricing, all while maintaining incentives for continued innovation. Whether this can be realized is hotly debated. Estimates suggest that bringing a biosimilar to market will cost between $\$ 10$ and $\$ 40$ million and take 6 to 9 years, compared with the $\$ 1$ to $\$ 2$ million price tag and 3-year time-frame for generics. ${ }^{9,10}$ In light of the clinical and economic implications, the risks and benefits must be carefully weighed so that clinicians can make informed decisions about biosimilars when they enter the market.

\section{Comparability}

Before marketing, generics must prove bioequivalence by showing that the active substance and characteristics of an agent are similar to its predecessor. ${ }^{11}$ For example, the pharmacokinetic range of a generic must be between $80 \%$ and $125 \%$ of the original. Large-scale clinical trials are often unnecessary because of the consistency with which generics can be reproduced. ${ }^{12,13}$ This differs from biosimilars, because factors such as pharmacokinetic equivalence are inadequate to ensure comparability. Manufacturers of biosimilars do not have access to the process through which the initial innovator is produced, making it impossible to replicate exactly. In addition, reliance on cell cultures and the manipulation of genetic material introduces variability into the process. Variations in development can lead to significant differences in isoforms, three-dimensional structures, glycosylation, and other important molecular characteristics. ${ }^{14-16}$ Although some variations are unlikely to be clinically meaningful, others may affect the immunogenicity or other clinically critical attribute of a drug.
Some leniency is already allowed, with innovators able to make small manufacturing changes without requiring further clinical testing, and the production process of agents may result in drift over time. ${ }^{17}$ Episodes of pure red cell aplasia (PRCA) related to anti-erythropoietin antibodies brought attention to this topic in the late 1990s. ${ }^{18,19}$ Eprex (Ortho-Biotech) was an epoetin alfa marketed outside the United States. In 1998, the formulation was altered to exclude albumin from production because of concerns about prion transmission. In addition, the company began using rubber stoppers to cap prefilled syringes at that time. During the next 5 years, more than 200 cases of PRCA were seen in renal patients receiving Eprex. The specific reason for the antibody production is still debated, but after the formulation and production changes were readdressed, episodes of PRCA no longer occurred. This history speaks to the impact of seemingly small changes to the production process.

More extensive clinical trials will be required for biosimilars. One critical question is whether noninferiority trials, which attempt to show that an agent is as efficacious and safe as the innovator product, will be adequate or whether equivalence studies will be required. Demonstration of superiority in a noninferiority trial could represent a lack of comparability, because consistent formulations should not result in improved outcomes. Findings of superiority could require further testing. Although equivalence studies require more patients, this design would increase the likelihood of approval if the results fall within the prespecified range. Other aspects of trial design are also being debated. Crossover studies have been advocated in which patients switch between innovators and biosimilars midway through the trial, attempting to prove that the outcomes are similar and the agents are truly interchangeable. Crossover studies would likely increase the complexity and cost of trials because of the infrastructure needed to implement the trial design and may decrease accrual.

Another point of contention is whether clinical data proving the equivalence of a biosimilar for a given indication can be extrapolated to other diseases or indications. For instance, would data showing the equivalence of a biosimilar to bevacizumab in colorectal cancer be adequate to allow its introduction in other cancer types? It has been suggested that, as long as the mechanisms are similar, a single 
approval will be adequate. However, in oncology, agents often target more than one pathway, and the mechanism with the greatest relevance to a specific disease can be unclear. The European experience provides insight into how these concerns are being addressed.

\section{European Experience}

The EU passed legislation in 2004 introducing a new regulatory path for biosimilars. The European Medicines Agency (EMEA) published the guidelines outlined in Figure 1, which have been used to introduce more than a dozen agents to the market. ${ }^{6,7,20}$ According to the guidances, approval is a stepwise process, beginning with preclinical studies of pharmacokinetics and pharmacodynamic data, followed by clinical trial enrollment, making it similar to the approval process for traditional biologics. ${ }^{20}$ The difference lies in the type and amount of clinical data generation that is required. Under the legislation, biosimilars must be shown to be of a "similar nature, in terms of quality, safety and efficacy" when compared with the innovator. ${ }^{6}$ A uniform approval process was not possible because of variations in end points and surrogate markers of response that are specific to a given drug or disease. The areas of consistency across treatments include the need to show appropriate quality, purity, and comparability of in vitro and in vivo pharmacokinetic and pharmacodynamic data. ${ }^{6,7,19}$ Class guidances have also been released, as shown in Figure 1, detailing the additional needs for specifics agents, such as granulocyte colony-simulating factor, erythropoietin, and insulin. ${ }^{21-24}$ The requirements differ significantly among products. For instance, randomized controlled trials of patients undergoing treatment were needed to evaluate epoetin biosimilars, whereas preclinical data coupled with studies of healthy volunteers were adequate for the introduction of insulin products.

In the EU, after a given indication is approved, regulation states that "the efficacy and safety of the biosimilar medicine may also have to be assessed using specific tests or studies for each disease." 25 However, this has not been consistently enforced, because biosimilars are often marketed across the same disease states as the original product without further trials. To help address concerns raised by the limited clinical experience before marketing, companies must submit a risk management program that includes pharmacovigilance and surveillance studies to ensure all of the safety signals are seen. ${ }^{20}$

Biosimilars have already been introduced in Europe, a few of which are used in oncology (Table 2). ${ }^{26}$ All monoclonal antibodies are still under patent protection, but they are nearing expiration in Europe. In light of this, the EMEA is in the process of updating its guidelines to outline specific requirements for these agents, because they are more complex than those introduced previously. ${ }^{27}$ The stringency of the process in the EU led to application withdrawals for 3 insulin products from Marvel Life Sciences (Harrow, UK) because of concerns regarding comparability to Humulin, and the rejection of 2 interferon agents (Alpheon and Biferonex, Biopartners, Cologne, Germany) because of concerns about the quality and efficacy of the products compared with the originator. ${ }^{28,29}$

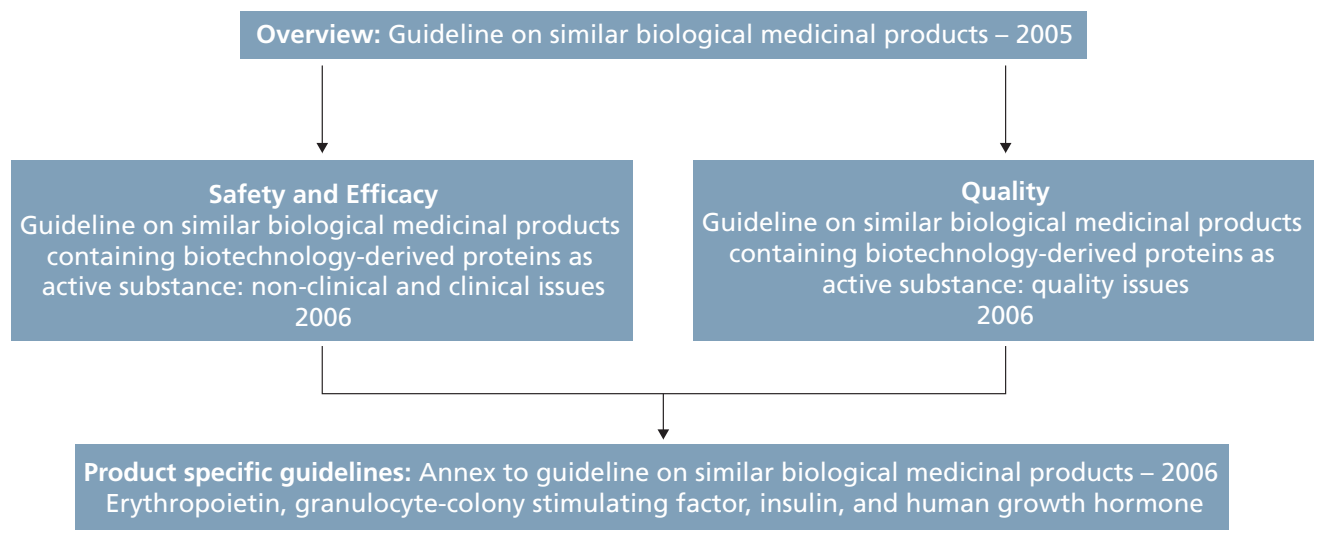

Figure 1 This figure depicts the guidelines released by the European Medicines Agency in the European Union in 2005 and 2006 to guide biosimilar development and how they relate to one another. 
Hirsch and Lyman

\begin{tabular}{|c|c|c|c|}
\hline International Generic & Trade Name of Biosimilar & Company & Date of Approval \\
\hline \multirow[t]{2}{*}{ Epoetin alfa } & Epoetin alfa Hexal & Hexal AG & August 2007 \\
\hline & Abseamed & $\begin{array}{l}\text { MEDICE Pharma GmbH \& } \\
\text { Co. KG }\end{array}$ & August 2007 \\
\hline \multirow[t]{2}{*}{ Epoetin zeta } & Silapo & STADA Arzneimittel AG & December 2007 \\
\hline & Retacrit & Hospira, Inc. & December 2007 \\
\hline \multirow[t]{6}{*}{ Filgrastim } & Ratiograstim & ratiopharm GmbH & September 2008 \\
\hline & Biograstim & CT Arzneimittel GmbH & September 2008 \\
\hline & Tevagrastim & $\begin{array}{l}\text { Teva Pharmaceutical } \\
\text { Industries Ltd. }\end{array}$ & September 2008 \\
\hline & Zarzio & Sandoz International GmbH & February 2009 \\
\hline & Filgrastim Hexal & Hexal AG & February 2009 \\
\hline & Nivestim & Hospira, Inc. & June 2010 \\
\hline \multirow[t]{2}{*}{ Epoetin theta } & Biopoin & CT Arzneimittel GmbH & October 2009 \\
\hline & Eporatio & ratiopharm GmbH & October 2009 \\
\hline
\end{tabular}

Among biologic agents used in oncology, 2 categories (granulocyte colony-stimulating factor and erythropoietin alfa) have experienced biosimilar entry at the time of patent expiration.

Data from European Medicines Agency. European public assements reports: cancer. 2011. Available at: http://www.ema.europa.eu. Accessed February 10, 2011.

\section{Patent Protection}

Although issues related to patent protection and data exclusivity were previously at the center of the debate on biologics, it was addressed with the passage of health reform legislation in the United States. Biopharmaceuticals were granted 12 years of data exclusivity, based largely on the work of Henry Grabowski at Duke University. He calculated that it takes between 12.9 and 16.2 years for a company to recoup its initial investment in a biologic, per the breakeven analysis shown in Figure 2.30 Because of the complexity of biologics, access to the initial clinical data on an agent is critical to achieve expedited approval for a follow-on agent, even after patent expiration. Patents do not allow consistent periods of protection as they are pursued before clinical trial enrollment. Particularly long and involved clinical trials for biologics can lead to shortened protection after approval, because a larger portion of the patent time may have expired. This contrasts with data exclusivity, which begins at FDA approval, guaranteeing 12 years of security on the market. Decisions regarding data exclusivity were meant to encourage investment and innovation by ensuring adequate returns on investment. This was firmly opposed by several patient rights groups and biosimilar producers but made it into the final law.

\section{Economics of Biosimilars}

The market for biosimilars in Europe differs from that for generics. There has been limited entry, adoption, and price influence because of the increased fixed costs of entry and the expense of production. Within 2 years of launch, biosimilar erythropoietins gained only $35 \%$ of the market, as opposed to the $90 \%$ substitution rate that generics can achieve in the first year. ${ }^{31}$ Because of the complexity of production, biosimilars are unlikely to achieve the price discounts of generics. Most experts estimate that they will likely be marketed at a $20 \%$ to $30 \%$ discount to the original products, whereas generics can achieve $75 \%$ discount rates. However, even a $20 \%$ discount on the $\$ 66$ billion spent in 2009 on the top 20 biologics is substantial. ${ }^{5}$ An analysis by the European Generic Medicines Agency in 2009 estimated that biosimilars generated $€ 1.4$ billion in savings in the EU that year. ${ }^{32} \mathrm{~A}$ separate evaluation estimated that a $20 \%$ discount on just 5 off-patent biologics would average $€ 1.6$ billion in yearly savings in the EU. ${ }^{33}$ Although yet to be seen, the U.S. Congressional Budget Office estimates that, once approved, biosimilars will save consumers an aggregate of $\$ 25$ billion per decade.

The increase in potential profits will encourage companies to enter the market as patents expire in 


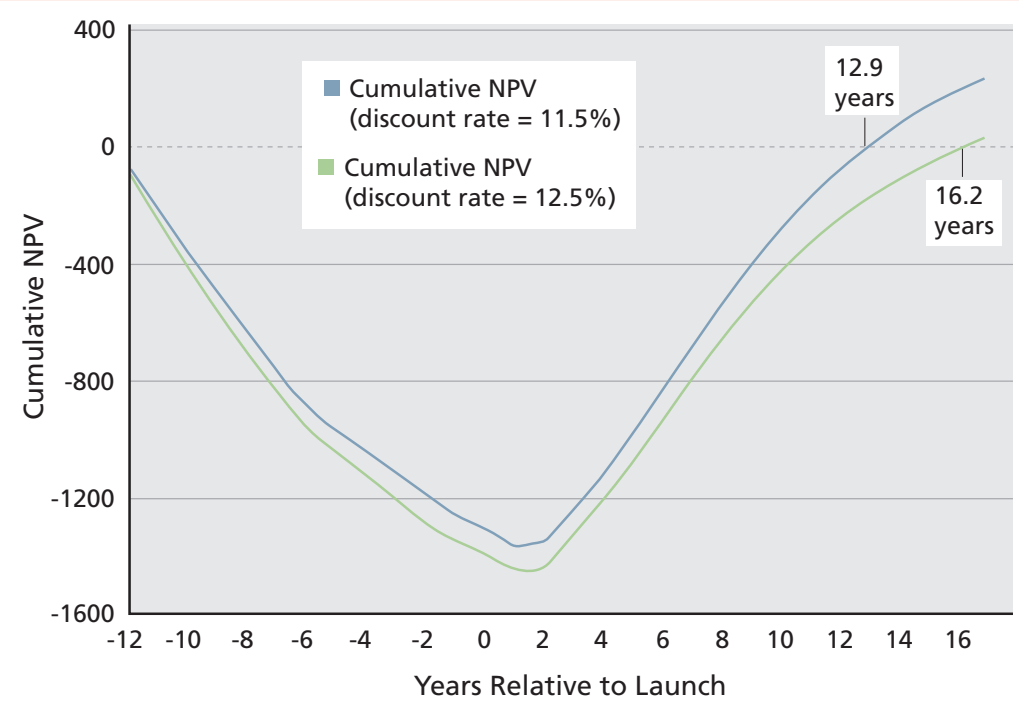

Figure 2 The figure depicts the net present value (NPV) of an agent from initial research and development investment to 18 years after launch. Calculations show that biologics require between 12.9 and 16.2 years to achieve a breakeven NPV. The different values are based on varying discount rates of $11.5 \%$ and $12.5 \%$, respectively.

From Grabowski H. Follow-on biologics: data exclusivity and the balance between innovation and competition. Nat Rev Drug Discov 2008;7:484. Reprinted by permission from Macmillian Publishers Ltd.

the United States. North America accounted for $39.8 \%$ of worldwide pharmaceutical sales in 2009 , whereas Europe was close behind at 30.6\%.34 With both markets open to biosimilars, the economics of entry become much more convincing as the profit potential more than doubles. The first monoclonal antibody biosimilar is expected to be rituximab. Teva Pharmaceuticals has announced that it has an agent ready to begin clinical trials in anticipation of its patent expiration in Europe as of 2013.34

How quickly and to what extent providers and hospitals will embrace biosimilars is unclear. Pharmacy and Therapeutics Committees will have a significant financial incentive to integrate biosimilars into their formularies as long as adequate safety and comparability data are available. Because hospitals are often paid a flat fee for care under the Medicare and Medicaid programs, decreased spending on biologics means significant potential savings. Community oncologists may embrace biosimilars as long as the financial incentives are aligned appropriately. However, comfort and lengthy experience with innovator molecules may influence decisions in clinical practice. Nevertheless, the economic motivations encouraging clinicians to use one agent over another should be minimized, allowing them to choose the agent they feel is best for a patient and the clinical community.

\section{Case Study: Myeloid Growth Factors}

The myeloid growth factors were among the initial biosimilars introduced in Europe, providing an excellent example of the strengths and weaknesses of the field. These agents are administered subcutaneously, starting 1 to 3 days after completion of cytotoxic therapy to reduce the severity and duration of neutropenia and the risk of febrile neutropenia. ${ }^{35}$ Several formulations of myeloid growth factors are on the market, yet many clinicians do not consider them interchangeable. Filgrastim, pegfilgrastim, and lenograstim differ in numerous ways, including their biologic characteristics, approved indications, and market share. ${ }^{36}$ For instance, filgrastim has been shown to achieve faster recovery from neutropenia versus lenograstim, whereas lenograstim use was shown to result in increased stem cell production..$^{37,38}$ Lenograstim is available in several countries but not in the United States. In addition, comparative studies between filgrastim and pegfilgrastim have shown differences..$^{39,40}$ Filgrastim use has decreased with the introduction of pegfilgrastim, which is associated with the greater convenience of once-per-cycle dosing.

The successful introduction of biosimilars into this space will require adequate price differentiation to overcome the convenience of longer-acting formulations that will remain under patient protection. More importantly, to overcome any hesitancy among 
Hirsch and Lyman

clinicians about the efficacy and safety of biosimilars, the new agent must have adequate clinical data showing comparability to the established agents in reducing the risk of severe febrile neutropenia.

In anticipation of access to the United States market, Hospira has pursued multiple studies comparing its biosimilar filgrastim (Nivestim) with Amgen's agent (Neupogen). Waller et al. ${ }^{41-43}$ published multiple studies in 2010 comparing the two, including a phase I study showing similar pharmacokinetic data between the agents, a phase I crossover study showing similar pharmacodynamic properties, and a phase III trial of 250 patients showing similar safety profiles and clinical end points, including duration of severe neutropenia, incidence of febrile neutropenia, and time to absolute neutrophil recovery. Another study compared the molecular characteristics, purity, and biologic activity of the agents in vivo, again showing similar profiles. ${ }^{44}$ This level of evidence is encouraging but insufficient to judge actual noninferiority. Therefore, until the FDA process is fully defined, the adequacy of these studies will remain unclear, as will the role of pharmacovigilance.

\section{Future Directions and Pharmacovigilance}

Steven Kozlowski, director of the Office of Biotechnology Products at the FDA, stated at a congressional hearing in 2009 that better analytic tools are needed to characterize critical aspects of biosimilars in vivo before the process can be trusted. ${ }^{17}$ Over time, it is anticipated that new laboratory techniques will be introduced which permit adequate in vivo comparisons of biologics and biosimilars. Retacrit is often used as an example as to why clinical testing is necessary. When the agent was being tested, preliminary bioequivalence data showed variations in potency between batches of the biosimilar and innovator products, and initial testing did not adequately establish the parameters of the biologics. ${ }^{45}$ The biggest concerns relating to comparability revolve around immunogenicity and potency.

One of the critical pieces of the puzzle will likely be pharmacovigilance. Although comparability can be shown with smaller trials, achieving adequate sample size requirements to assess the adverse event profile, including the immunogenicity of an agent, is unlikely. The biggest concern is that changes in the production process could alter the immune response of patients to follow on agents, which would not be seen in a few hundred patients. In the EU, postmarketing studies help address this shortcoming and will be necessary in the United States also. A 2008 Food and Drug Law Journal article by DiMartino et al. ${ }^{46}$ discusses several ways in which pharmacovigilance could be implemented in the United States. However, these would each take significant investment and initiative. The most promising strategy uses Medicare claims data. If modifications are made, the hope is that an "early warning system" could be implemented to detect and report events, allowing earlier introduction of agents because adverse events could be seen and addressed. The implementation of electronic health records may help make this a reality.

Several unanswered questions remain for biosimilars and their approval in the United States. What will the details of the approval process entail? Is adequate pharmacovigilance possible? How robust will the cost savings actually be? What degree of interchangeability will be required? Despite these uncertainties, the entry of biosimilars into the United States is a certainty, and clinicians must begin to understand when and how to use them. Their entry will present both opportunities and responsibilities. The pressure to reduce health care costs in the United States is steadily growing. However, biosimilars will be routinely used only when clinicians are convinced of their safety and efficacy. This will be a difficult but essential balance to achieve moving forward.

\section{References}

1. Giezen TJ, Mantel-Teeuwisse AK, Straus SM, et al. Safety-related regulatory actions for biologicals approved in the United States and the European Union. JAMA 2008;300:1887-1896.

2. Roger SD. Biosimilars: how similar or dissimilar are they? Nephrology (Carlton) 2006;11:341-346.

3. Chirino AJ, Mire-Sluis A. Characterizing biological products and assessing comparability following manufacturing changes. Nat Biotechnol 2004;22:1383-1391.

4. Schellekens H. Factors influencing the immunogenicity of therapeutic proteins. Nephrol Dial Transplant 2005;20(Suppl 6):vi3-9.

5. Top 20 biologics 2009. Available at: http://www.pipelinereview. com/free-downloads/top_20_biologics_2009_rd_pipeline_news. pdf Accessed February 8, 2011.

6. European Medicines Agency. Guideline on similar biological medicinal products. 2005. Available at: www.ema.europa.eu/pdfs/ human/biosimilar/043704en.pdf. Accessed February 9, 2011.

7. European Medicines Agency. Guideline on similar biological medicinal products containing biotechnology-derived proteins as active substance: quality issues. 2006. Available at: http:// 


\section{Biosimilars}

www.ema.europa.eu/docs/en_GB/document_library/Scientific_ guideline/2009/09/WC500003953.pdf. Accessed February 9, 2011.

8. Mellstedt $\mathrm{H}$, Niederwieser D, Ludwig $\mathrm{H}$. The challenge of biosimilars. Ann Oncol 2008;19:411-419.

9. Grabowsk H. Patents and New Product Development in the Pharmaceutical and Biotechnology Industries. Duke University, Department of Economics. Available at: http://econ.duke.edu/ Papers/Other/Grabowski/Patents.pdf. Accessed May 20, 2011.

10. Grabowski H, Cockburn I, Long G. The market for follow-on biologics: how will it evolve? Health Aff (Millwood) 2006;25:12911301.

11. Mossinghoff GJ. Overview of the Hatch-Waxman Act and its impact on the drug development process. Food Drug Law J 1999;54:187-194.

12. Center for Drug Evalation and Research. CDER guidance for industry: statistical approaches to establishing bioequivalence. 2001. Available at: www.fda.gov/downloads/Drugs/ GuidanceComplianceRegulatoryInformation/Guidances/ ucm070244.pdf. Accessed February 10, 2011.

13. Davit BM, Nwakama PE, Buehler GJ, et al. Comparing generic and innovator drugs: a review of 12 years of bioequivalence data from the United States Food and Drug Administration. Ann Pharmacother 2009;43:1583-1597.

14. Schellekens H, Ryff JC. 'Biogenerics': the off-patent biotech products. Trends Pharmacol Sci 2002;23:119-121.

15. Schellekens $H$. Bioequivalence and the immunogenicity of biopharmaceuticals. Nat Rev Drug Discov 2002;1:457-462.

16. Hesse F, Wagner R. Developments and improvements in the manufacturing of human therapeutics with mammalian cell cultures. Trends Biotechnol 2000;18:173-180.

17. Mullard A. Hearing shines spotlight on biosimilar controversies. Nat Rev Drug Discov 2010;9:905-906.

18. Boven K, Stryker S, Knight J, et al. The increased incidence of pure red cell aplasia with an Eprex formulation in uncoated rubber stopper syringes. Kidney Int 2005;67:2346-2353.

19. Jelkmann W. Biosimilar epoetins and other "follow-on" biologics: update on the European experiences. Am J Hematol 2010;85:771780 .

20. European Medicines Agency. Pharmacovigilance - Medicinal products for human use and veterinary medicinal products. 2004. Available at: http://ec.europa.eu/health/documents/eudralex/vol-9/ index_en.htm. Accessed February 10, 2011.

21. European Medicines Agency. Guidance on similar medicinal products containing recombinant erythropoietins. 2006. Available at: http://www.ema.europa.eu/pdfs/human/biosimilar/9452605en. pdf. Accessed February 10. 2011.

22. European Medicines Agency. Guideline on non-clinical and clinical development of similar biological medicinal products containing recombinant erythropoietins (revision). 2009. Available at: http:// www.ema.europa.eu/pdfs/human/biosimilar/30163608endraft.pdf. Accessed February 10, 2011.

23. Euroepan Medicines Agency. Guidance on similar medicinal products containing recombinant granulocyte-colony stimulating factor. 2006. Available at: http://www.tga.gov.au/docs/pdf/euguide/ bmwp/3132905en.pdf. Accessed February 10, 2011.

24. European Medicines Agency. Guidance on similar medicinal products of recombinant human soluble insulin. 2006. Available at: http://www.ema.europa.eu/pdfs/human/biosimilar/3277505en. pdf. Accessed February 10, 2011.
25. European Medicines Agency. Questions and Answers on biosimilar medicines (similar biological medicinal products). 2008. Available at: http://www.emea.europa.eu/pdfs/human/pcwp/7456206en.pdf. Accessed February 10, 2011.

26. European Medicines Agency. European public assements reports: cancer. 2011. Available at: http://www.ema.europa.eu/ema/index. jsp?curl=/pages/medicines/landing/epar_search.jsp\& murl=menus/ medicines/medicines.jsp\&mid=WCOb01ac058001d125\&searchT $\mathrm{ab}=\&$ alreadyLoaded $=$ true $\&$ status $=$ Authorised $\&$ status $=$ Withdraw n\&status $=$ Suspended\&status $=$ Refused $\&$ keyword $=$ Enter + keyword $s \&$ search Type $=$ name $\&$ taxonomyPath $=$ Diseases $\&$ treeNumber $=\& c$ urrentCategory $=$ Cancer\&searchGeneric Type $=$ generics. Accessed February 10, 2011.

27. Reichert JM, Beck A, Iyer H. European Medicines Agency workshop on biosimilar monoclonal antibodies: July 2, 2009, London, UK. MAbs 2009;1:394-416.

28. European Medicines Agency. Questions and answers on the withdrawal of the marketing authorisation application for Insulin Human Rapid Marvel, Insulin Human Long Marvel, Insulin Human 30/70 Mix Marvel. 2008. Available at: http://www.ema. europa.eu/docs/en_GB/document_library/Medicine_QA/2009/11/ WC500015341.pdf. Accessed February 10, 2011.

29. European Medicines Agency. Questions and answers on recommendation for the refusal of the marketing authorisation for Biferonex. 2009. Available at: http://www.ema.europa.eu/ pdfs/human/opinion/BiferonexQ\&A_9112009en.pdf. Accessed February 10, 2011.

30. Grabowski H. Follow-on biologics: data exclusivity and the balance between innovation and competition. Nat Rev Drug Discov 2008;7:479-488.

31. Hodgson J. WHO guidelines presage US biosimilars legislation? Nat Biotechnol 2009;27:963-965.

32. European Generic Medicines Association. Vision 2015: the EGA's thoughts on how to improve the legal and regulatory framework for generic and biosimilar medicines. 2010. Available at: http://www. egagenerics.com/doc/EGA_Vision_2015.pdf. Accessed February 10, 2011.

33. Oldham T. Strategies for entering the biosimilar market. In: Oldham T, ed. Biosimilars-Evolution or Revolution. London, England: Biopharm Knowledge Publishing; 2006.

34. Ledford H. 'Biosimilar' drugs poised to penetrate market. Nature 2010;468:18-19.

35. Crawford J, Armitage J, Balducci L, et al. Myeloid growth factors. J Natl Compr Canc Netw 2009;7:64-83.

36. Orciuolo E, Buda G, Marturano E, et al. Lenograstim reduces the incidence of febrile episodes, when compared with filgrastim, in multiple myeloma patients undergoing stem cell mobilization. Leuk Res 2011;35:899-903.

37. Kim IH, Park SK, Suh OK, Oh JM. Comparison of lenograstim and filgrastim on haematological effects after autologous peripheral blood stem cell transplantation with high-dose chemotherapy. Curr Med Res Opin 2003;19:753-759.

38. Watts MJ, Addison I, Long SG, et al. Crossover study of the haematological effects and pharmacokinetics of glycosylated and non-glycosylated G-CSF in healthy volunteers. Br J Haematol 1997;98:474-479.

39. Pinto L, Liu Z, Doan Q, et al. Comparison of pegfilgrastim with filgrastim on febrile neutropenia, grade IV neutropenia and bone pain: a meta-analysis of randomized controlled trials. Curr Med Res Opin 2007;23:2283-2295.

40. Lyman GH, Lalla A, Barron RL, Dubois RW. Cost-effectiveness of 
pegfilgrastim versus filgrastim primary prophylaxis in women with early-stage breast cancer receiving chemotherapy in the United States. Clin Ther 2009;31:1092-1104.

41. Waller CF, Semiglazov VF, Tjulandin S, et al. A phase III randomized equivalence study of biosimilar filgrastim versus Amgen filgrastim in patients receiving myelosuppressive chemotherapy for breast cancer. Onkologie 2010;33:504-511.

42. Waller CF, Bronchud M, Mair S, Challand R. Pharmacokinetic profiles of a biosimilar filgrastim and Amgen filgrastim: results from a randomized, phase I trial. Ann Hematol 2010;89:927933.

43. Waller CF, Bronchud M, Mair S, Challand R. Comparison of the pharmacodynamic profiles of a biosimilar filgrastim and Amgen filgrastim: results from a randomized, phase I trial. Ann Hematol 2010;89:971-978.

44. Skrlin A, Radic I, Vuletic M, et al. Comparison of the physicochemical properties of a biosimilar filgrastim with those of reference filgrastim. Biologicals 2010;38:557-566.

45. Schellekens H. Assessing the bioequivalence of biosimilars the Retacrit case. Drug Discov Today 2009;14:495-499.

46. DiMartino LD, Curtis LH, Williams RL, et al. Using Medicare administrative data to conduct postmarketing surveillance of follow-on biologics: issues and opportunities. Food Drug Law J 2008;63:891-900. 


\section{CME Activity: Biosimilars}

To obtain credit, you should first read the journal article. After reading the article, you should be able to answer the following, related, multiple-choice questions. To complete the questions (with a minimum $70 \%$ passing score) and earn continuing medical education (CME) credit, please go to www.medscape.org/journal/jnccn.

Credit cannot be obtained for tests completed on paper, although you may use the worksheet below to keep a record of your answers. You must be a registered user on Medscape.org. If you are not registered on Medscape.org, please click on the New Users: Free Registration link on the left hand side of the website to register.

Only one answer is correct for each question. Once you successfully answer all post-test questions you will be able to view and/or print your certificate. For questions regarding the content of this activity, contact the accredited provider, CME@medscape.net. For technical assistance, contact CME@webmd.net.

American Medical Association's Physician's Recognition Award (AMA PRA) credits are accepted in the US as evidence of participation in CME activities. For further information on this award, please refer to http://www.ama-assn.org/ama/pub/category/2922. html. The AMA has determined that physicians not licensed in the US who participate in this CME activity are eligible for AMA PRA Category 1 Credits $^{\mathrm{TM}}$. Through agreements that the AMA has made with agencies in some countries, AMA PRA credit may be acceptable as evidence of participation in CME activities. If you are not licensed in the U.S., please complete the questions online, print the AMA PRA CME credit certificate, and present it to your national medical association for review.
1. Which of the following statements regarding biologic agents is most accurate?
A. Almost all of the top-selling biologic agents are used in the field of rheumatology
B. The Federal Food, Drug, and Cosmetic Act al- lows for approval of biologics
C. Production processes for particular biologics are generally easily replicated with current technology
D. Innovator biologics are allowed 12 years on the market before biosimilars can be introduced

2. In Europe, which of the following outcomes is most consistently required of biosimilar agents (compared with the innovator biologic agents) for their approval?
A. Equivalent outcomes in clinical data
B. Similar in vivo pharmacodynamic data
C. Similar rates of adverse events in the first 30 days of use
D. Similar rates of adverse events in the first 10,000 patients to receive the biosimilar agent

3. Which of the following statements regarding the economics of biosimilars is most accurate?
A. Biosimilars will not be offered at the same deep discount as generic drugs
B. Biosimilars now command the vast majority of the European market
C. Hospitals in the United States will not experi- ence significant savings with biosimilars
D. The healthcare system in the United States will not experience significant savings with biosimilars

4. Which of the following methods of biovigilance is most promising to assure the quality of biosimilars in the United States?
A. An online registration system for oncologists with voluntary reporting of data
B. Establishment of a pharmacy-based database
C. Monthly monitoring of event data from compa- nies producing biosimilars
D. Review of Medicare claims data

\section{Activity Evaluation}

1. The activity supported the learning objectives. Strongly Disagree 1 2 3 Strongly Agree $4 \quad 5$

2. The material was organized clearly for learning to occur.
Strongly Disagree
1 2 3

3. The content learned from this activity will impact my practice.

Strongly Disagree

$\begin{array}{lllll}1 & 2 & 3 & 4 & 5\end{array}$

4. The activity was presented objectively and free of commercial bias.

Strongly Disagree

$\begin{array}{lllrr}1 & 2 & 3 & 4 & 5\end{array}$

To obtain credit, visit Medscape online at http://www.medscapecme.org/journal/jnccn. 